\title{
Designing a Bretton Woods Institution to Address Climate Change
}

\section{Citation}

Aldy, Joseph. 2012. Designing a Bretton Woods Institution to Address Climate Change. HKS Faculty Research Working Paper Series RWP12-017, John F. Kennedy School of Government, Harvard University

\section{Published Version}

http://web.hks.harvard.edu/publications/workingpapers/citation.aspx?Publd=8381

\section{Permanent link}

http://nrs.harvard.edu/urn-3:HUL.InstRepos:8830777

\section{Terms of Use}

This article was downloaded from Harvard University's DASH repository, and is made available under the terms and conditions applicable to Other Posted Material, as set forth at http:// nrs.harvard.edu/urn-3:HUL.InstRepos:dash.current.terms-of-use\#LAA

\section{Share Your Story}

The Harvard community has made this article openly available.

Please share how this access benefits you. Submit a story.

\section{Accessibility}




\section{Designing a Bretton Woods Institution to Address Climate Change Faculty Research Working Paper Series}

\section{Joseph E. Aldy}

Harvard Kennedy School, Resources for the Future, and National

Bureau of Economic Research

\section{May 2012}

\section{RWP12-017}

The views expressed in the HKS Faculty Research Working Paper Series are those of the author(s) and do not necessarily reflect those of the John F. Kennedy School of Government or of Harvard University. Faculty Research Working Papers have not undergone formal review and approval. Such papers are included in this series to elicit feedback and to encourage debate on important public policy challenges. Copyright belongs to the author(s). Papers may be downloaded for personal use only. 


\section{Designing a Bretton Woods Institution to Address Climate Change}

Joseph E. Aldy

Harvard Kennedy School

Resources for the Future

National Bureau of Economic Research

May 17, 2012 Draft

John F. Kennedy School of Government, Harvard University, 79 JFK Street, Cambridge, MA 02138, joseph aldy@hks.harvard.edu. Billy Pizer and participants at the 2008 Third Atlantic Workshop on Energy and Environmental Economics provided comments on an earlier draft. Sarah Szambelan and Sarah Cannon provided valuable research assistance. 


\title{
Designing a Bretton Woods Institution to Address Climate Change
}

\begin{abstract}
The information structure of the climate change policy collaboration problem necessitates the design of institutions to enhance public knowledge about nations' commitments, policies, and outcomes. The international community has addressed this kind of problem in a wide array of other contexts from which lessons can be drawn and applied to international climate policy. Based on these experiences and the characteristics of a successful international climate policy architecture, this paper proposes the design of a "Bretton Woods Climate Institution" (BWCl). This BWCI should implement a serious system of national and global policy surveillance. This surveillance would include an evaluation by independent experts of the various policy commitments nations make in international negotiations to assess whether nations delivered on their commitments and to examine the impacts of these actions on various climate change risk reduction margins, such as emission abatement and adaptation. Such a surveillance scheme should be consultative in nature, to allow give and take among experts and among nations engaged in the international climate policy effort. Based on this surveillance, the institution should promote best policy practices. In addition, the BWCI should provide a means to channel some financing for investments in climate change risk mitigation activities in developing countries. By making funds conditional on agreeing to policy surveillance, such an approach would create an incentive for transparent evaluations of policies and actions. Moreover, access to market-based climate policy schemes, such as the Clean Development Mechanism and emission trading, could be predicated on countries agreeing to participate in policy surveillance.
\end{abstract}




\section{Designing a Bretton Woods Institution to Address Climate Change}

\section{Introduction}

Mitigating climate change risks will require some form of global effort to limit emissions, adapt to a changing climate, and geo-engineer the global climate system. These three policy approaches - prevention, adaptation, and remediation - involve, to varying degrees, little incentive to account for the external impacts of decision-making by individuals, firms, and nation-states. Thus, a "successful" international climate policy architecture, at a minimum, will need to promote collaboration among nation-states that results in sovereign policies and actions to reduce climate change risks by modifying individuals' and firms' incentives.

Successful collaboration requires more than a simple, initial agreement. The dynamics of learning about climate change and learning about the effectiveness of various risk mitigation measures will necessitate a number of rounds of collaboration among nations. Given the strong incentives for free-riding, what are the characteristics of an international climate policy architecture that could enable repeated collaboration in climate change risk reduction efforts?

A climate policy framework that represents an effective effort in combating climate change, is perceived as fair by all participating nations, and is considered legitimate and thus encourages broad participation is more likely to be successful than a regime that lacks these characteristics. An effective, fair, legitimate policy architecture promotes trust and establishes credibility in the agreement. As one nation takes actions to mitigate climate change risks, it can trust that other nations are also taking on actions that will effectively reduce the risks of climate change. As one nation takes actions, it can assess the actions of its peers and determine if their actions are comparable and fair. A framework is legitimated by a positive cycle of nations taking fair, effective actions that elicits broader and more complete participation.

The failure to deliver an effective, fair, legitimate climate change policy through the Kyoto framework is evident in the inability of the international community to negotiate a successor to the Kyoto Protocol's first commitment period and the evolution toward a pledge and review system established under the 2009 Copenhagen Accord. Indeed, the excessive focus on normative goals instead of institutional design in international climate negotiations has undermined the legitimacy of the current multilateral regime, and this absence of legitimacy then facilitates questioning about fairness and effectiveness of commitments. It is not that there are disagreements over what constitutes an effective or fair approach (there are); it's that the current regime does not provide the institutional means to even assess outcomes before subjecting these outcomes to a normative assessment of effectiveness and fairness.

The information structure of the climate change policy collaboration problem necessitates the design of institutions to enhance public knowledge about nations' commitments, policies, and outcomes. The international community has addressed this kind of problem in a wide array of other contexts from which lessons can be drawn and applied to international climate policy. Based on these experiences and the characteristics of a successful international climate policy architecture, this paper proposes the design of a "Bretton Woods Climate Institution" (BWCI).

Such an institution should have three primary functions to enhance the legitimacy of multilateral climate policy efforts. First, this $\mathrm{BWCl}$ should implement a serious system of 
national and global policy surveillance. This surveillance would include an evaluation by independent experts of the various policy commitments nations make in international negotiations to assess whether nations delivered on their commitments and to examine the impacts of these actions on various climate change risk reduction margins, such as emission abatement and adaptation. It would also include an aggregate assessment of the net effect of nations' efforts to inform consideration of whether these actions are sufficient to combat climate change. As in other multilateral contexts, such a surveillance scheme should be consultative in nature, to allow give and take among experts and among nations engaged in the international climate policy effort.

While some may perceive the primary role of the Bretton Woods institutions, the IMF and the World Bank, as one of financing, policy surveillance is an important part of their missions. In the international climate context, policy surveillance is critical because of the need to promote trust and build credibility in an agreement among nations about each of their respective commitments. In this sense, the envisioned $\mathrm{BWCl}$ may better reflect the system of international trade policy surveillance, which evolved from a failed attempt to design an international trade organization at Bretton Woods into the current regime under the WTO.

Second, the institution should promote best policy practices. This would reflect its surveillance role, from which an assessment and publication of the most effective policies could inform nations' deliberations over the kinds of policies and actions they may consider for domestic implementation. In particular, such assessments should account for the implications of legal, economic, and cultural contexts that can impact the relative effectiveness of various policy instruments and actions across nations.

Third, the institution should provide a means to channel some financing for investments in climate change risk mitigation activities in developing countries. By making funds conditional on agreeing to policy surveillance, such an approach would create an incentive for transparent evaluations of policies and actions. Since the majority of international finance associated with addressing climate change will likely run through the private sector, this financing mechanism would serve as a complement to these private sector efforts. Leveraging finance to enhance transparency could also be extended by the setting of eligibility rules for existing developed country export and development finance programs. For example, the U.S. Ex-Im Bank and the U.S. Overseas Private Investment Corporation could agree to provide loan guarantees and political insurance only for use in developing countries that have agreed to policy surveillance under this new institution. Moreover, access to market-based climate policy schemes, such as the Clean Development Mechanism and emission trading, could be predicated on countries agreeing to participate in policy surveillance.

The next section of this paper draws from game theory, international relations, and legal scholarship to make the case why promoting policy transparency through surveillance can enhance the legitimacy of and foster more effective international climate change policy agreements. The third section details the shortcomings in the current international climate policy framework for reporting, review, and verification that undermine its legitimacy. The fourth section surveys various international systems of policy surveillance on economic, trade, energy, and environmental issues and presents lessons to inform a climate policy surveillance regime. The fifth section presents the detailed proposal for a "Bretton Woods Climate 
Institution" and discusses how such an institution could complement bottom-up and top-down approaches to international climate policy architectures. The sixth section concludes.

\section{Surveillance and Agreements}

\section{Public Information and Repeated Games}

More than 50 years ago, Professor Schelling wrote about the economic attributes of negotiations. Signaling the seriousness of commitment is often a precondition for securing an agreement among multiple parties. This can be challenging in some contexts, such as international negotiations given the significant deference to sovereigns and limited tools for coercing a state to take actions beyond what it intends to undertake voluntarily. Schelling suggests that transparency on a party's ex ante pledge and ex post outcome can enhance the credibility of commitments:

"A potent means of commitment, and sometimes the only means, is the pledge of one's reputation.... But to commit in this fashion publicity is required. Both the initial offer and the final outcome would have to be known; and if secrecy surrounds either point, or if the outcome is inherently not observable, the device is unavailable" (Schelling 1956, 288).

Schelling stresses that agreements may need to be structured on what is observable, even if that is only correlated with the intended objective of the negotiation, in order to ensure that one can observe compliance with the agreement. In addition, Schelling's take on the role of trust in repeated negotiations can inform the structure of climate negotiations given the dynamic nature of the climate change policy problem:

"What makes many agreements enforceable is only the recognition of future opportunities for agreement that will be eliminated if mutual trust is not created and maintained, and whose value outweighs the momentary gain from cheating in the present instance" (Schelling 1956, 301-302).

Indeed, these insights have since been formalized in a variety of papers on the so-called Folk Theorems in game theory, which show that repeated games with public information can yield socially efficient, stable agreements if parties to these agreements are sufficiently patient (Fudenberg and Maskn 1986). In the context of international climate coalition games, Barrett's (1994) dismal one-period finding that the country-specific benefits and costs of climate mitigation will likely undermine the stability of any climate coalition in excess of three parties is softened in a repeated game environment and, with sufficient patience, larger coalitions are possible.

The key to these findings is that actions by all parties are easily and perfectly observed. In the current climate policy regime, this is certainly not the case, in which most nations' climate policies and greenhouse gas emissions are neither reported, nor observed, nor reviewed formally under the UN Framework Convention on Climate Change (more on this in the next section). 
Under weaker assumptions, agreements among parties could be sustained even with imperfect public information (e.g., Green and Porter 1984 and Fudenberg et al. 1994) and "almost-public" private information (e.g., Malaith and Morris 2002). Even in these cases, observation of signals of action (whether commonly shared, i.e., public, or individually acquired by each party, i.e., private) is still necessary, and as these signals convey less information on a party's actions, the more difficult it is to maintain a stable agreement. As Barrett (2003) notes in his discussion of monitoring in international environmental agreements, "transparency is of fundamental importance in a repeated game" (p. 284).

\section{The Use of Public Information in International Agreements}

The information structure of repeated negotiations is a critical element determining the stability of negotiated coalitions. Keohane (1994) emphasizes the importance of information-producing institutions to facilitate collaboration among nations. In particular, he notes that "more extensive arrangements for monitoring others' behavior" is required in collaboration games and can promote the reciprocity necessary to secure agreement in such games (Keohane 1994, 20). Wettestad (2007) also notes the relationship between public information about nations' performance under an agreement and the trust it builds: "good monitoring and verification of practices in international institutions are important in building trust between and among cooperating parties, and in strengthening wider societal confidence" (975). The legitimacy of the international agreement may rest on the caliber, credibility, and independence of the implementing institutions (Bodansky 2007).

Public information about a nation's actions can empower its leaders and stakeholders to call on and pressure that nation to deliver on its commitments. Political leaders who push for their nations to take on more ambitious climate change risk reduction policies could benefit from an institution collecting and publicizing information on their actions. By providing an independent assessment of a country's effort and a comparison with the effort of its peers, regular surveillance can legitimize domestic policies (Francois 2001).

Improving information on commitments and outcomes supports informal and formal mechanisms of peer review and peer pressure (Pagani 2002). Nations may initiate an informal bilateral dialogue with those nations lagging far behind (to pressure them to do more) or demonstrating progressive leadership and accomplishment (to learn how to follow their lead effectively). Such information may also enable comparisons among nations that facilitate peer pressure in the next round of negotiations.

International institutions of information collection and dissemination can lower the costs of an international agreement. Some international non-governmental organizations have developed the technical capacity to assist governments with monitoring (Hempel 1996). Technical and financial assistance for key elements of capacity building could enable improved monitoring, reporting, and evaluation in developing countries (Keohane 1994). International institutions can formally undertake monitoring that lowers the transaction costs of an agreement (Haas et al. 1993).

Some nations may send mixed or misleading signals about their outcomes through various public reporting mechanisms. A variety of means have evolved to mitigate this problem that could inform the design of a surveillance institution. Some non-governmental organizations can 
serve as external checks on national reporting and evaluation programs by providing their own monitoring information to the public and the media. External monitoring of a country's emissions can occur through remote sensing technologies (Litfin 1999) as well as through the use of correlated data sources, such as on fossil fuel consumption, economic activity, etc.

The information compiled on parties' actions and outcomes does not need to meet the standard of a legal compliance mechanism. Indeed, few nations would subject themselves to such a legal mechanism, nor do the parameters of international environmental treaties impose such a requirement. Such information may "contain deviance within acceptable levels"' (Klabbers $2007,1004)$. The challenge lies in designing legitimate institutions that provide the necessary public information to mitigate deviations from agreements on climate policy.

\section{The Need for Better Surveillance to Inform Global Climate Change Policy}

The current international climate change policy architecture suffers from a dearth of information on countries' contributions to climate change and the effectiveness of their efforts to combat the problem. Under the UN Framework Convention on Climate Change and the Kyoto Protocol, the responsibility for mitigating emissions and reporting on emissions has fallen almost exclusively on developed countries. Indeed, the policy rationale in UNFCCC agreements for developed countries to take the first mitigation efforts steps has reflected negotiating rhetoric as opposed to the evidence about the relative current and historic contributions to climate change. The failure of what is primarily an emission mitigation treaty to track emissions of all large countries reinforces the rhetorical bias in the negotiations. Moreover, the UNFCCC provides an insufficient institutional process for evaluating countries' efforts and a single, deeply flawed metric for assessing the comparability of effort among nations.

\section{The Disconnect Between the Rhetorical Basis for Policy and Statistical Evidence}

The absence of a credible monitoring regime has created an information vacuum in which northsouth rhetoric, as opposed to experience and evidence, has informed the design of policy. For example, at the first Conference of the Parties (COP-1) of the Framework Convention in 1995, the global community agreed to the Berlin Mandate (United Nations 1995). This decision established a negotiating mandate for emission targets for developed (Annex I) countries, while explicitly noting that Non-Annex I countries would not face any new commitments. The mandate notes that this negotiating process "shall be guided" in part by "the fact that the largest share of historical and current global emissions of greenhouse gases has originated in developed countries" (United Nations 1995; emphasis added). This contradicts independent estimates that show annual Non-Annex I countries' greenhouse gas emissions exceeded Annex I countries' emissions by more than 12 percent in 1995 (WRI 2012).

In the 2010 Cancun Agreements, this developed countries' "largest share of historical" global emissions reference returned. Yet, Annex I countries only contributed to 54 percent of global greenhouse gas emissions over 1900-2005, and Annex I and Non-Annex I contributions to cumulative emissions since 1900 should reach parity by 2020 (Hohne et al. 2007). When expressly stated rationale for policy design runs contrary to scientific evidence, the legitimacy of the international agreement is undermined. It also reveals a lack of interest in scientific evidence to motivate policy and a lack of interest in collecting and analyzing scientific evidence about the climate change problem. 
The UNFCCC monitoring regime is grossly inadequate. Under the treaty, nations communicate to the UN reports on their vulnerability to climate change, policies to address climate change, greenhouse gas emissions, etc. Annex I countries have submitted five national communications in the eighteen years the UNFCCC has been in effect, while a majority of developing countries including China and India - have submitted only one such report (through March 1, 2012). While developed countries submit annual emissions reports, developing countries are exempt from reporting annual greenhouse gas emissions to the UNFCCC despite the dramatic growth in such emissions.

For example, China's most recent greenhouse gas emissions report submitted to the UN Framework Convention on Climate Change is for the 1994 calendar year (UNFCCC 2012; as of March 1, 2012,). Between 1995 and 2010, China is estimated to have emitted about 75 billion metric tons of carbon dioxide from fossil fuel combustion and cement production, which exceeds the cumulative emissions of any developed country over the entire $20^{\text {th }}$ century, except for the United States (calculated by author using data from Boden and Blasing 2012 and Boden et al. 2011). This failure to report does not reflect some burdensome or technically challenging emissions record-keeping obstacle. Under the Montreal Protocol, China has reported annual detailed ozone-depleting substances consumption inventory data over the 1990-2010 period (UNEP 2012).

This reflects the differentiation in the reporting and review regime under the UNFCCC. Developed countries submit annual emission reports, pursuant to established guidelines and subject to expert review. In contrast, developing countries emissions reports are made as a part of their infrequent national communications, and are neither subject to the same data standards as developed countries nor undergo expert review (Breidenich and Bodansky 2009). Even the regular reporting of developed countries emissions is insufficient to characterize the effectiveness of emission mitigation actions in these countries (Ellis and Larsen 2008). The UNFCCC has not published guidelines for the review of developed countries national communications, and these expert reviews do not provide the means to verify the impact of emission mitigation measures (Breidenich and Bodansky 2009).

\section{The Absence of Credible Metrics to Assess Comparability of Effort}

In order for a set of countries to perceive their contribution to mitigating climate change as fair, they need a means for acquiring information on each others' actions and emissions and a basis for comparing the effort. The absence of credible, legitimate means for comparing effort plays out both in the determination of the set of countries that should take on emission commitments and in the ex post evaluation of countries' performance in delivering on those commitments.

Many have argued that the focus of UNFCCC mitigation goals on industrialized countries reflects their greater wealth and higher emissions (current, historic, and per capita). Yet, about 50 NonAnnex I countries have higher per capita incomes than the poorest Annex I country. In addition, about 40 Non-Annex I countries rank higher on the Human Development Index than the lowest ranked Annex I country (Aldy and Stavins 2010a). Forty-four Non-Annex I countries had higher per capita carbon dioxide emissions than the lowest ranked Annex I country (U.S. EIA 2012b). 
Comparing the effort to mitigate emissions remains a daunting question. The most "successful" countries, in terms of achieving emissions below 1990 levels, are the economies in transition. The shutting down of much of the old Soviet industrial infrastructure and the transformation from planned to market economies has resulted in dramatic emission reductions. Russia's 2000 greenhouse gas emissions were 32 percent below 1990 levels. In 2007, the year before the start of the Kyoto commitment period, the old EU-15 had aggregate emissions 5 percent below 1990 levels, while the expanded EU-27 had emissions 11 percent below 1990 levels, illustrating how far below 1990 levels central and eastern European countries' emissions had fallen. The world cannot learn from this "success" in designing future climate policy; these countries did not achieve the emission reductions through innovation emission abatement policies, but rather through painful economic restructuring. Thus, comparing current emissions to 1990 provides a very noisy signal of a nation's effort.

Is the United States a climate laggard because it has not ratified the Kyoto Protocol? By 2009, U.S. greenhouse gas emissions were 7 percent below 1997 levels. Since the 1997 Kyoto Conference, the growth rate of U.S. greenhouse gas emissions ranks seventeenth out of the 36 Annex I nations with commitments under Kyoto, and this growth rate is lower than for ten EU member states (Figure 1). This is not simply a function of the recent economic recession. In 2010, U.S. fossil fuel carbon dioxide emissions were 11 percent lower (nearly 700 million metric tons of carbon dioxide lower), but GDP was about 9 percent higher than was forecast by the U.S. Energy Information Administration in 1997 in the lead up to the Kyoto negotiations (U.S. EIA 1997, 2012a; Figure 2).

\section{Adequacy of Effort}

The surveillance program under the UNFCCC does not report a global aggregate greenhouse gas emissions measure. Indeed, there is neither reporting nor monitoring mechanisms that would enable the UNFCCC to publish a global emission estimate. For an international treaty focused on stabilizing atmospheric greenhouse gas concentrations, it is striking that it does not track the flow of global greenhouse gas emissions.

Independent estimates of carbon dioxide emissions from fossil fuel combustion provide little evidence that the UNFCCC has delivered adequate effort. Global emissions in 2010 were about 48 percent greater than they were in 1992 (Boden and Blasing 2012 and Boden et al. 2011).

Global emissions grew about 2.8 percent annually in the decade after the 1997 Kyoto negotiations, dramatically faster than the 1.2 percent annual rate in the lead-up to the Kyoto Conference.

\section{Some Recent Signs of Progress}

The international community has taken some recent steps to address this reporting and analysis vacuum. World leaders agreed to design Measurement, Reporting, and Verification systems and a system of International Consultations and Analysis for developing countries mitigation efforts in the 2009 Copenhagen Accord. The initial steps towards implementing the leaders' vision at the 2010 Cancun and 2011 Durban climate talks highlight the potential for a more extensive and rigorous climate policy reporting and review mechanism. 


\section{Lessons on Surveillance from Other International Policy Regimes}

Policy surveillance serves as a key element of a broad array of international policy regimes. International organizations undertake regular assessments of domestic policy design, implementation, and outcomes in, inter alia, economic policy, trade policy, energy subsidies, trade in endangered species. These experiences can provide important lessons to inform the design of an effective system of climate policy surveillance. The following subsections provide brief summaries of and identify lessons from policy surveillance regimes in a variety of contexts, and a closing synthesis of international policy surveillance.

\section{International Monetary Fund Article IV Consultations}

The International Monetary Fund undertakes country-, regional-, and global-level economic surveillance (IMF 2001; Schafer 2006). Individual country surveillance occurs annually under socalled Article IV consultations. The IMF conducts regular surveillance of the global economy - in effect, an assessment of the aggregate impact of various economic, monetary, and fiscal policies of the member countries - and publishes the World Economic Outlook typically twice per year.

An Article IV consultation includes an annual visit by IMF economists and experts to the member country, with interim discussions when necessary. Countries are required to produce information to the IMF to enable the review of its economic environment and relevant economic policies. After a country visit, the IMF expert team compiles a report that serves as the basis for a peer review by the Executive Board, which includes 24 country directors representing member countries or groups of countries. A summary of the Board discussion and the report are typically published, and it is the emerging norm that countries agree to the publication of their full Article IV staff report. Making public these reports enables stakeholders to push for better economic policies in their respective countries and improves the quality of the IMF review product by effectively subjecting the reviewers to external assessment (Fischer 1999).

The IMF also supports standards for data dissemination and codes for good policy practice that can facilitate annual surveillance and also benefit member countries in their design and implementation of economic policy. Such standards provide transparent, timely, and measurable metrics for evaluating policy performance and identifying potential economic vulnerabilities. The IMF emphasizes the value in implementing such standards and codes to communicate clearly to the markets and other countries on a country's economic situation. Conditioning financing from the IMF (or even more broadly from other international financial institutions) on the adoption and adherence of standards and codes of practice could improve the quality of the surveillance regime (Fischer 1999).

\section{OECD Economic Surveys}

The OECD facilitates peer reviews of member states' economic policies every one to two years (OECD 2003; Schafer 2006). As a part of this effort, a team of experts from the OECD Secretariat compiles a draft report of the relevant policies for the country under review. The expert team typically visits the country under review, draws data from a variety of public and private sources, and employs the latest research to evaluate the country's economic policy program. A 
delegation from the country under review responds to the draft report in a meeting of all OECD member states. At this meeting, two so-called lead examiners are drawn from the membership of the OECD to initiate the discussion of the draft report's findings, the response by the country under review, and the report's recommendations for policy reforms. After these two peer reviewers question the country under review, the entire membership has the opportunity to discuss various elements of economic policy with that country's delegation. The final report reflects this discussion and must secure agreement among all OECD members before it is completed. The policy reviews are then made available to the public.

A distinctive element of the OECD review mechanism is the focus on peer review. The OECD employs peer review in a number of policy contexts beyond this example of economic policy review, and it has identified several structural elements common to its peer review processes, including an agreed set of principles, standards and criteria for evaluating performance, and an assessment of a country's performance in implementing policy recommendations. Providing a forum for member states to engage one another through peer review can facilitate learning about effective policy practice and promote understanding about countries' individual policy design and implementation. As a review among peers, it clearly serves as a facilitative process, not a tribunal or compliance mechanism, and thus could enable more candid dialogue among participants.

\section{WTO Trade Policy Review Mechanism}

WTO members are subject to a regular review of their trade policies (Mavroidis 1992). The four countries with the largest share of world trade undergo policy review every two years, while the next sixteen participate in reviews four years, and all other countries take part reviews every six years. Thus, differentiation in the frequency of review reflects a country's relative contribution to global trade. The objectives of the Trade Policy Review Mechanism (TPRM) are to promote adherence to commitments in multilateral and plurilateral trade agreements and increase transparency to facilitate a smoother functioning trade regime (Annex 3, Marrakech Accord).

The TPRM involves the preparation of a report by a given member country on its trade policies and a report drafted by a team of experts at the WTO Secretariat. The WTO Trade Policy Review Body provides guidance for country reporting, including a template to structure the regular reports to the WTO. In addition, developing countries may solicit technical assistance from the Secretariat in preparation of its trade policy reports. The WTO Secretariat expert team typically visits the country under review and draws from multiple sources - government data, third-party data sources, data in the public domain - in compiling its assessment of the country's trade policy.

An active give-and-take occurs with the country under review through two procedures. First, the country under review must respond in writing to questions it receives from the WTO expert review team. Second, the Trade Policy Review Body, comprised of all WTO members, receives the Secretariat's report on the country under review and then hosts a delegation from that country to participate in a meeting to discuss and explain the findings in the report. The final versions of the reports submitted by the country under review and the WTO expert review team are published.

Montreal Protocol Reporting on Ozone-Depleting Substances 
Under the Montreal Protocol and related agreements focused on reducing the production and consumption of ozone-depleting substances (ODS), countries report regularly on such ODS outcome data to the United Nations Environment Programme. Through March 2012, more than 190 countries have reported their ODS consumption data to UNEP for the year 2010, and more than 180 countries have reported annual ODS consumption for at least the past 15 years (UNEP 2012). This enables credible estimation of global ODS consumption, informed assessment of consumption over time both globally and by nation to illustrate performance relative to policy goals, and a public, transparent record to facilitate identification of policy leaders and laggards. This stands in sharp contrast to the UNFCCC process, in which only three developing countries (two of which are current OECD members, but classified as Non-Annex I under the UNFCCC) had submitted more than one national communication, the document that includes developing country emissions data and hence only one submission of a national greenhouse gas emission inventory, by the time of the 2009 Copenhagen climate talks (Breidenich and Bodansky 2009).

The Montreal Protocol surveillance program has a well-defined process and data standards for reporting, as well as a system of reviews of national policies that has strengthened the monitoring and transparency of the agreement (Hampson 1995). The Montreal Protocol Secretariat analyzes the annual national reports and publishes summary compliance reports before the annual international negotiations under this agreement. In some cases, experts employed data compiled by the World Meteorological Organization's Global Ozone Observing System, established in 1957, to verify the ODS data submitted by individual nations (Wettestad 2007). This enhanced system of reporting and review can facilitate "naming and shaming" in the context of an agreement that lacks a strong compliance mechanism, which is true of most international agreements (Hampson 1995).

The Secretariat also serves to enhance the capacity, especially in developing countries, to monitor and report their ODS consumption data. By elaborating procedures for tracking and reporting ODS data, providing data reporting templates, and explaining ways to improve domestic monitoring, the Secretariat facilitated developing country reporting. While these efforts lowered the costs and eliminated potential barriers to timely reporting, the Montreal Protocol surveillance process also increased the costs for failing to submit adequate ODS data reports by linking access to financing for projects to reduce ODS consumption to satisfying the reporting requirements (Wettestad 2007).

\section{G-20 Fossil Fuel Subsidies Agreement Implementation and Review}

In contrast to the previous policy surveillance programs that focus on a reporting and review infrastructure built on treaty organizations' own cadre of experts, several international agreements rely on external, third party experts to review countries' actions. First, consider the 2009 Pittsburgh G-20 commitment to eliminate fossil fuel subsidies (IEA et al. 2010). The leaders of the twenty largest developed and developing nations agreed to "phase out and rationalize over the medium term inefficient fossil fuel subsidies while providing targeted support to the poorest" (G20 Leaders 2009). The G-20 leaders also called on all nations to eliminate their fossil fuel subsidies, and later that fall at the 2009 Singapore APEC meeting, leaders also echoed the call to phase out such subsidies. 
Leaders have agreed to many things in various "G-\#" declarations and communiqués over the years, but the "G-\#" processes do not provide any system for compliance and enforcement. Instead, leaders can increase the cost of failing to deliver on their commitments by making such failure more transparent. In the context of the fossil fuel subsidies agreement, leaders established processes of implementation and third-party expert review to promote such transparency. As a part of the G-20 agreement, leaders tasked energy and finance ministers to identify their nation's fossil fuel subsidies, develop a plan for eliminating these subsidies, and report back to leaders by the following year's summit. The G-20 published a summary report of each member's identified fossil fuel subsidies and the plan for eliminating them at the $2010 \mathrm{G}$ 20 meeting in Toronto. Since then, leaders have continued to task energy and finance ministers to continue their efforts and report back regularly.

To complement this self-reporting, the G-20 leaders also tasked four international organizations - the International Energy Agency (IEA), the Organisation for Economic Co-operation and Development (OECD), the Organization of Petroleum Exporting Countries (OPEC), and the World Bank - to undertake their own, joint assessment of fossil fuel subsidies. This includes an examination of individual countries' subsidies as well as the aggregate economic, energy, and environmental impacts of the sum of these nations' subsidies. These international organizations published their joint report to G-20 leaders at the 2010 Toronto meeting and have continued to provide analysis and reviews of countries' implementation strategies pursuant to tasking by the G-20.

This third party reporting provides an independent reference for countries' identification of subsidies and an independent review of their progress in rationalizing fossil fuel pricing. This process enhances transparency on implementation, and can empower domestic stakeholders as well as peer nations' within the G-20 to apply pressure and invoke moral suasion to push a country to deliver on its commitment. This process can also highlight the successful efforts to reduce such subsidies and to illustrate possible strategies that other countries could emulate as they attempt to move forward in implementing their commitments. Relying on external experts at established and recognized international organizations also mitigates concerns about politicization of the evaluation and verification mechanism and allows for a rapid ramping up of the review process that would not be possible if a new bureaucracy had to be constructed from scratch. A potential limitation of relying on existing international organizations, however, may be the legitimacy of those with incomplete memberships. For example, some developing countries may question analysis and reviews by the International Energy Agency, whose membership is comprised of developed nations.

\section{Monitoring Trade in Endangered Species}

The implementation of the monitoring system under the Convention on International Trade in Endangered Species (CITES) represents a second example of independent review and verification of an international agreement (Wettestad 2007). Under CITES, nations submit regular reports on trade in covered species (annually) and on relevant policies impacting trade in endangered species (biennially). In the 1970s, CITES effectively turned to international nongovernmental organizations - the World Conservation Union (IUCN) and the World Wildlife Fund - to provide independent reviews of these annual national reports. This independent verification system has evolved into what is now referred to as the Trade Records Analysis of Flora and Fauna in Commerce (TRAFFIC) monitoring network. In this case, the international 
policy community agreed to defer to existing expertise outside of an international bureaucracy to assess and verify compliance with international agreements.

\section{Synthesis on International Policy Surveillance Experience}

Extensive international policy surveillance occurs in a number of economic, energy, and environmental policy contexts. Table 1 summarizes the key elements of a sample of these surveillance systems, and compares them with the status quo system of surveillance under the UN Framework Convention on Climate Change.

The table reveals a few stark differences between the climate policy surveillance and these other regimes. First, the IMF, OECD, WTO, and G-20 regimes rely on both expert review and peer review, whereas the UNFCCC regime is only an expert review. Second, the expert reviews of economic, trade, and subsidy policies are undertaken by career staff of their respective institutions, while the UNFCCC review typically draws in an ad hoc nature from governmentsponsored experts (from academia, business, and government sectors) to conduct a review. Third, the UNFCCC review applies only to the industrialized countries, while the various economic policy surveillance systems apply to all member states to that institution. Fourth, the provision of standards and reporting templates can improve the transparency of the reporting and review and enhance surveillance effectiveness. While this is common among the economic policy surveillance and the UNFCCC process for industrialized nations, it does not apply to the occasional reporting of emissions by developed countries under the UNFCCC.

\section{Proposal for a Bretton Woods Climate Institution}

The Bretton Woods Climate Institution would provide for surveillance of climate change policies - on emission mitigation, adaptation, and, if necessary, geoengineering - and climate policyrelated outcomes. It would draw the lessons of the most effective climate policies from this surveillance and publish recommended best policy practices. International climate finance would be conditioned on a country regularly undergoing surveillance to provide an incentive for participation. After elaborating the details of the proposal, this section closes with a discussion of how this institution could complement an array of bottom-up and top-down international climate policy architectures.

\section{Surveillance Mechanism}

The objective of the surveillance mechanism is to provide transparent, rigorous, credible assessments of individual and global performance in the effort to combat climate change.

The surveillance mechanism would require active engagement by the country under review, an expert review team, and representatives of other countries participating in the peer review. The $\mathrm{BWCl}$ would establish standards for monitoring and reporting data on greenhouse gas emissions and climate policy performance. These could be de novo standards or the adoption of existing, rigorous standards (e.g., IPCC standards on emission inventories). The $\mathrm{BWCl}$ would provide guidance to facilitate monitoring and reporting of the relevant data. In addition, the country under review would submit a report summarizing its climate policy performance that would serve as a key input to the work of the expert review team. 
The expert review team would make an in-country visit to meet with government officials, relevant stakeholders, and to collect data. In addition, the expert review team would consult other sources of data to inform its assessment. The BWCl would develop and publish metrics for performance evaluation to frame the country reviews. This team then drafts a report for consideration by the peers of the nation under review.

An Executive Board that reflects the contributions to the $\mathrm{BWCl}$ and geographic diversity would meet regularly to discuss the draft reports by the expert review teams. One developed and one developing country representative would be randomly chosen from the Executive Board to serve as "peer examiners" in the discussion of the country's review. A delegation from that country would participate in this discussion and respond to questions raised by the examiners, and then in an open forum with the entire Executive Board. Based on this discussion, the expert review team finalizes the report, which must be approved by a consensus of the Executive Board (except for the country under review if it happens to be a Board member at that time), and it is made publicly available.

Global reviews would occur annually. These would draw from annual reporting of greenhouse gas emissions from every country, the policy surveillance undertaken that year, as well as thematic analyses. These reviews would also provide near-term forecast for greenhouse gas emissions growth and identify policy reforms that could reduce emissions.

The frequency of individual country policy reviews would vary with the level of current greenhouse gas emissions. The largest ten sources of greenhouse gas emissions in 2010 would undergo annual surveillance. The next twenty sources by size would undergo review every two years. All other countries would participate in reviews every three years.

An individual country can solicit a review of another country. If this second country does not consent to review, then the $\mathrm{BWCl}$ would undertake the review without an in-country visit. In this case, the $\mathrm{BWCl}$ would compile information from available sources and draft a report for review by the Executive Board. This would be akin to the G-20 tasked reports by the international organizations.

A country may request resources to build capacity to participate more effectively in the surveillance regime. The $\mathrm{BWCl}$ would encourage rotations of in-country staff to the institution to refine analytic skills and develop a better understanding for the operation of the surveillance mechanism.

The Executive Board would identify an external advisory board of experts who would periodically review the surveillance mechanism. This advisory board, by reviewing the reviewers, can identify ways to improve the quality of analysis, enhance the transparency of compiled information, and develop more effective ways to promote best policy practice.

A professional bureaucracy would be recruited to undertake the analysis of the various forms of policy commitments. This would extend beyond simply measuring greenhouse gas emissions. The professional staff would undertake analysis of all countries' climate change policies, including abatement policies, financial contributions to and receipts from the clean technology fund, support for and effectiveness of adaptation programs, research funds for geoengineering, 
etc. In the near term, such an institution could be staffed by current experts at other international organizations.

This institution would require significant resources to scale up and operate. Countries participating in the $\mathrm{BWCl}$ would make regular contributions, akin to existing international organizations. New revenue streams could also be tapped, perhaps based on one of the ideas identified by the Advisory Group on Finance (2010). Countries requesting the review of another country would need to provide the resources for the review.

\section{Best Policy Practice}

Developed and emerging economies have substantial experience in implementing policies that can affect the investment in more energy-efficient or low-carbon technologies. Drawing lessons from these successes and failures can inform the design of new policies in all countries, but especially those in developing countries that may lack the institutional capacity to fully evaluate and compare all policy options. Establishing a set of "best practice" policies can draw from past efforts to promote the deployment of energy-efficient technologies, and tailor guidance for countries' specific economic and cultural circumstances.

The initial set of "best practice" policies should focus on promoting no regrets and low-cost measures. This would draw attention to policies that facilitate investment in more energyefficient technologies, since they deliver a stream of returns over time in terms of lower expenditures on fuel and power. It could also highlight opportunities for countries to address multiple policy objectives, such as climate change mitigation and local air quality improvement or climate change mitigation and energy security. These efforts should also consider means to promote the diffusion of technologies to facilitate adaptation to climate change.

Consider the example of reforming energy subsidies. Removing subsidies on the consumption of energy and the production of fossil fuels could significantly reduce carbon dioxide emissions; full implementation of the G-20 fossil fuel subsidies agreement could lower global emissions by 7 percent by 2020 (IEA et al. 2010). Such efforts would free up fiscal resources that could finance other socially-desirable activities. Phasing out subsidies could yield comparable price changes on energy as imposing carbon pricing programs in developed countries, and deliver economic benefits by stimulating a more efficient allocation of investment that can accelerate economic growth. Rationalizing fossil fuel pricing could also improve air quality.

The $\mathrm{BWCl}$ could promote policy learning by supporting randomized field experiments with new policies. For example, the $\mathrm{BWCl}$ could provide technical guidance on the ways to design, implement, and evaluate such experiments. In addition, the $\mathrm{BWCl}$ could provide financing to cover the incremental costs of undertaking such experiments and, to leverage an initial set of experimental efforts, additional resources could be provided.

The BWCl could publicize best policy practices through a variety of outlets. First, the regular reviews of individual countries climate policy programs could include recommendations of policies appropriate to the geographic, cultural, and economic context of that country. Second, best policy practices could be highlighted in annual aggregate surveillance reports and in occasional special thematic reports. 


\section{International Climate Finance}

The BWCl could establish basic eligibility standards for international climate finance. In particular, a country must participate in the surveillance regime in order to receive climate finance resources. This could reflect a formal integration of the $\mathrm{BWCl}$ and the Climate Investment Funds at the World Bank, the Green Climate Fund under the UNFCCC, the climate activities of the Global Environment Facility, etc. A more practical outcome is a set of agreements between the $\mathrm{BWCl}$ and these existing financial institutions to ensure that recipient countries participate in policy surveillance. In addition, donor countries could agree to employ the $\mathrm{BWCl}$ as the scorekeeper for various forms of climate finance, and thus subject their climate finance programs to surveillance.

Since the international climate finance space is already much further developed - in terms of institutions, resources, and projects in progress - than international climate surveillance, I will only briefly describe two ideas for climate finance as a means to leverage participation in the surveillance regime.

First, a clean technology fund could support investment in emission mitigation projects and policies in developing countries. The clean technology fund should complement, not substitute, for efforts that would occur otherwise through existing private and carbon markets.

The centralized nature of a fund highlights an opportunity to make investments that can maximize the mitigation potential for a given amount of resources. Specifically, the clean technology fund could address criticisms of the CDM that it has created windfall profits for some firms (Wara 2007), by financing projects at a level sufficient to provide a reasonable, but not extraordinary profit for the developing country firm. A reverse auction could serve as the vehicle for allocating the fund's resources (Keeler and Thompson 2010). Under such a mechanism, the fund would solicit bids from firms in developing countries. The bids would represent the amount the firm would require in a subsidy in order to invest and use a new, climate-friendly technology. The fund could start with the lowest cost bids and work up the bid profile until it has exhausted all the resources dedicated for the specific technology auction. The challenge in effectively implementing a reverse auction lies in identifying technologies and projects that are low-cost but would not have happened in the absence of the fund.

Given fiscal constraints in many OECD countries, the clean technology fund could be financed through an auction of supplemental emission credits to firms regulated by cap-and-trade programs in the developed world (or some other revenue raiser, for example those identified by the Advisory Group on Finance 2010). These credits would not be backed by a ton-for-ton abatement through specific projects. Instead, the expectation is that the broad portfolio of investment from the clean technology fund will deliver emission abatement in developing countries that will more than offset the higher emissions allowed in OECD cap-and-trade programs through the auctioned credits. Prudent management of donors' resources could attract developed country engagement and secure their participation in surveillance.

Second, financing for adaptation could elicit extensive participation by the least developed countries in the surveillance regime. The de facto international "insurance" for major natural disasters - such as 1998 Hurricane Mitch in Central America and 2008 Cyclone Nargis in Myanmar - is ad hoc in terms of the speed, scale, and source of support. An alternative 
approach could be an explicit insurance fund for least developed countries financed through catastrophic risk bonds. The bonds supporting this fund would be issued by developed countries, but payouts of the bonds require three kinds of actions by developing countries in addition to a qualifying natural disaster. First, to mitigate the incentive for moral hazard, these least developed countries must make some investments to reduce their exposure to the relevant climate-related natural disasters (hurricanes, droughts, floods, etc.). Second, participating countries must also implement some "no regrets" emission mitigation policies identified through the best policy practices assessment of the $\mathrm{BWCl}$. The policies could be fairly modest, and their direct effect could be negligible on the global climate, but they would establish the norm for abatement action by the very poorest countries. This norm then creates the floor for the minimum acceptable abatement effort by wealthier developing countries, so it could encourage more ambitious actions by those with greater resources. Third, the participating countries would agree to undergo surveillance of these risk reduction and emission mitigation efforts.

The least developed countries participating in this insurance fund could make claims for a standard class of disasters; there would be no requirement to attribute an event to climate change. The insurance fund would need to enlist broad, geographic participation in order to diversify risk. Given the lack of actuarial tables for climate change, management of the fund will depend on the improved knowledge base on climate risks and impacts.

\section{Integration with Various Climate Policy Architectures}

Such a climate Bretton Woods-like institution could complement a variety international climate policy architectures (for examples, refer to Aldy et al. 2003, Aldy and Stavins 2007, and Aldy and Stavins 2010). First, the BWCl could serve as a significant scaling up in rigor and scope of the existing emissions and policy surveillance regime under the UNFCCC. Thus, a top-down treaty organization could create such an institution for receiving emissions and policy reports, undertaking evaluations of parties' climate policy programs, and publishing reviews of individuals parties' actions and assessments of the aggregate effort to address climate change.

Second, it could inform the design of new, top-down international agreements on emission mitigation. For example, Frankel (2010) proposes a formulaic approach to determining emission targets as a function of incomes and per capita emissions. Such an approach requires rigorously evaluated data from participating countries in order to set targets, and then to assess compliance with them. The $\mathrm{BWCl}$ could play the role of compiling necessary data for the ex ante target-setting exercise and the ex post performance evaluation. Cooper (2010) advocates for an international climate policy regime premised on harmonization of domestic carbon taxes. The BWCl could serve the role that Cooper would assign to the IMF of reviewing countries' carbon taxes (and related energy tax programs) to ensure that economic activity around the world faces a common carbon price.

Third, a BWCl could facilitate the evolution of a bottom-up climate policy architecture along two dimensions. For example, the pledge and review system reflected in the Copenhagen Accord and the Cancun Agreements would certainly benefit from a more rigorous review program than exists under the status quo. Indeed, this is evident in the agreement for "international consultations and analysis" of developing country mitigation actions, policies, and goals as well as in the assessment of the scaling up of international climate finance. A credible, independent 
assessment of countries' efforts to deliver on mitigation and financing goals can increase trust among parties and build support for this approach to climate change policy.

In addition, an assessment of domestic cap-and-trade programs by the $\mathrm{BWCl}$ could serve as a necessary condition for linking of any two countries' (or regions') cap-and-trade programs. The linking of any two programs would likely require some kind of mutual assessment to ensure comparable integrity. The BWCl could perform this evaluation, as an independent, expert third party, for any two cap-and-trade programs considering linking. Indeed, linking provisions of authorizing legislation or regulations could specifically call on the $\mathrm{BWCl}$ to perform this evaluation.

Fourth, various governments could rely on the $\mathrm{BWCl}$ for analyses to inform the implementation of their respective domestic climate change policies. A donor country may use BWCI assessments of the policies and actions of those countries receiving international climate finance to determine how to direct a next round of finance. Indeed, a donor country could require any recipient country to undergo periodic evaluation by the $\mathrm{BWCl}$ to remain eligible for that donor country's climate financing. Donor countries could reach an agreement as a group on such an approach to create a strong incentive for developing countries to participate in the review process of the $\mathrm{BWCl}$.

In addition, some domestic climate policies may include some kind of border measure, such as a border carbon tax, on the emission intensity of imported goods from countries without comparable domestic climate change programs. For example, the 2009 American Clean Energy and Security Act (H.R. 2454) in the U.S. House of Representatives included such a border measure and required an assessment of the adequacy of other countries' domestic climate programs to determine the applicability of the border measure. A given country could require nations exporting goods to that country to undergo periodic evaluation by the $\mathrm{BWCl}$ as a condition for a waiver of the border tax. The BWCl could agree to undertake such a review of trade partners if the country soliciting review under goes a comparable assessment. This creates an explicit opportunity for comparison of domestic programs consistent with the WTO's non-discriminatory application standard for evaluating a border measure. Thus, countries have the incentive to solicit reviews for legitimate (as opposed to political grandstanding) purposes, since an adverse comparison by the BWCI for the soliciting country would likely weaken dramatically that country's position before a WTO tribunal.

\section{Conclusion}

Designing and implementing a new Bretton Woods Climate Institution would signal a new seriousness by the international community in its effort to combat climate change. Such an institution, on par with existing institutions to address international financial, trade, and development challenges, could serve as an important foundation for the next steps to address climate change.

Countries are likely to participate in an international effort to address climate change that they believe requires them to make a fair contribution to a global effort that is up to the challenge. This will necessitate efforts to assess the comparability of effort among countries and the adequacy of the aggregate effort. To build trust, peers must undertake comparable policies. 
Such an evaluation requires meaningful metrics of policy implementation and outcomes. The envisioned policy surveillance under the BWCI would provide both an ex ante analysis of proposed policy commitments, to promote credibility at international negotiations when countries propose their next steps, and an ex post assessment of whether a country complied with its policy commitments.

Assessments of effort can also provide a rigorous basis for identifying best policy practice and to report on the results of various policy experimentation. This can accelerate the learning process, especially for developing and emerging economies, as they gain knowledge from the leaders' initial efforts to abate emissions, promote adaptation, and conduct research on geoengineering.

Finally, this institution should be designed and implemented in way that creates incentives for countries to undergo surveillance willingly. Independent evaluation by experts can provide the legitimacy necessary to elicit support by participating nations. Conditioning international climate finance on participation in policy surveillance can induce broader participation. Providing an open access option for individual countries to request reviews as a component of their domestic policy-making - such as in donor resource allocation and border tax waiver decisions - could induce even the more reluctant nations to submit to $\mathrm{BWCl}$ surveillance. Further consideration of the design of the institution could promote even stronger incentives for countries to cooperate and actively support a more rigorous and extensive system of surveillance. 


\section{References}

Advisory Group on Finance. 2010. Report of the Secretary-General's High-Level Advisory Group on Climate Change Financing. New York: United Nations.

Aldy, Joseph E. 2004. "Saving the Planet Cost-Effectively: The Role of Economic Analysis in Climate Change Mitigation Policy." In: R. Lutter and J.F. Shogren, eds. Painting the White House Green: Rationalizing Environmental Policy Inside the Executive Office of the President. Washington, DC: Resources for the Future Press.

Aldy, Joseph E., Scott Barrett, and Robert N. Stavins. 2003. "Thirteen Plus One: A Comparison of Global Climate Policy Architectures." Climate Policy 3: 373-397.

Aldy, Joseph E. and Robert N. Stavins, eds. 2007. Architectures for Agreement: Addressing Global Climate Change in the Post-Kyoto World. Cambridge: Cambridge University Press.

Aldy, Joseph E. and Robert N. Stavins. 2010a. "Introduction." In: J.E. Aldy and R.N. Stavins, eds., Post-Kyoto International Climate Policy: Implementing Architectures for Agreement. Cambridge: Cambridge University Press.

Aldy, Joseph E. and Robert N. Stavins, eds. 2010b. Post-Kyoto International Climate Policy: Implementing Architectures for Agreement. Cambridge: Cambridge University Press.

Barrett, Scott. 1994. "Self-Enforcing International Environmental Agreements." Oxford Economic Papers 46: 878-894.

Barrett, Scott. 2003. Environment and Statecraft: The Strategy of Environmental TreatyMaking. Oxford: Oxford University Press.

Bodansky, Daniel. 2007. "Legitimacy." In: Bodansky, Daniel, Jutta Brunee, and Ellen Hey, eds. The Oxford Handbook of International Environmental Law, Oxford: Oxford University Press, 704722.

Boden, Tom and T.J. Blasing. 2012. Preliminary 2009 and 2010 Global and National Estimates of Carbon Emissions from Fossil Fuel Combustion and Cement Manufacture. Carbon Dioxide Information Analysis Center, Oak Ridge National Laboratory. Accessed February 19, 2012. Internet: http://cdiac.ornl.gov/trends/emis/perlim 20092010 estimates.html.

Boden, T.A., G. Marland, and R.J. Andres. 2011. Global, Regional, and National Fossil Fuel CO2 Emissions. Carbon Dioxide Information Analysis Center, Oak Ridge National Laboratory. Accessed February 19, 2012. Internet: http://cdiac.ornl.gov/trends/emis/overview 2008.html.

Breidenich, Clare and Daniel Bodansky. 2009. Measurement, Reporting and Verification in a Post-2012 Climate Agreement. Pew Center on Global Climate Change Report, April. Arlington, VA: Pew Center.

Cooper, Richard N. 2010. "The Case for Charges on Greenhouse Gases." In: J.E. Aldy and R.N. 
Stavins, eds., Post-Kyoto International Climate Policy: Implementing Architectures for Agreement. Cambridge: Cambridge University Press.

Ellis, Jane and Kate Larsen. 2008. Measurement, Reporting, and Verification of Mitigation Actions and Commitments. OECD and IEA Publication COM/ENV/EPOC/IEA/SLT(2008)1. Paris: OECD and IEA.

Fischer, Stanley. 1999. "Reforming the International Financial System." The Economic Journal 109: F557-F576.

Francois, J.F. 2001. "Trade Policy Transparency and Investor Confidence: Some Implications for an Effective Trade Policy Review Mechanism." Review of International Economics 9(2): 303-316.

Frankel, Jeffrey. 2010. "An Elaborated Proposal for a Global Climate Policy Architecture: Specific Formulas and Emission Targets for All Countries in All Decades." In: J.E. Aldy and R.N. Stavins, eds., Post-Kyoto International Climate Policy: Implementing Architectures for Agreement.

Cambridge: Cambridge University Press.

Fudenberg, Drew and Eric Maskin. 1986. "The Folk Theorem in Repeated Games with Discounting or with Incomplete Information." Econometrica 54(3): 533-554.

Fudenberg, Drew, David Levine, and Eric Maskin. 1994. "The Folk Theorem with Imperfect Public Information." Econometrica 62(5): 997-1039.

G-20 Leaders Declaration. 2009. Pittsburgh, PA, September 25.

Green, Edward J. and Robert H. Porter. 1984. "Noncooperative Collusion Under Imperfect Information." Econometrica 52(1): 87-100.

Haas, P.R., R.O. Keohane, and M.A. Levy, eds. 1993. Institutions for the Earth: Sources of Effective International Environmental Protection. Cambridge: MIT Press.

Hampson, F.O. 1995. Multilateral Negotiations: Lessons from Arms Control, Trade, and the Environment. Baltimore: The Johns Hopkins University.

Hempel, L.C. 1996. Environmental Governance: The Global Challenge. Washington: Island Press.

Hohne, Niklas, Joyce Penner, Michael Prather, Jan Fuglestvedt, Jason Lowe, and Guoquan Hu. 2007. Summary Report of the Ad Hoc Group for Modelling and Assessment of Contributions to Climate Change (MATCH). November 7. Accessed February 17, 2012. Internet: http://www.match-info.net/data/MATCH\%20summary\%20report.pdf

International Energy Agency, Organization of Petroleum Exporting Countries, Organisation of Economic Co-operation and Development, and the World Bank. 2010. Analysis of the Scope of Energy Subsidies and Suggestions of the G-20 Initiative. Joint report prepared for submission to the G-20 Summit Meeting, Toronto, Canada, June 26-27, 2010. 
International Monetary Fund. 2001. Annual Report 2001. Washington, DC: IMF.

Keeler, Andrew G. and Alexander Thompson. 2010. "Industrialized-Country Mitigation Policy and Resource Transfers to Developing Countries: Improving and Expanding Greenhouse Gas Offsets." In: J.E. Aldy and R.N. Stavins, eds., Post-Kyoto International Climate Policy: Implementing Architectures for Agreement. Cambridge: Cambridge University Press.

Keohane, R.O. 1994. "Against Hierarchy: An Institutional Approach to International Environmental Protection." In: Complex Cooperation: Institutions and Processes in International Resource Management. Oslo: Scandinavian University Press.

Klabbers, Jan. 2007. "Compliance Procedures.” In: Bodansky, Daniel, Jutta Brunee, and Ellen Hey, eds. The Oxford Handbook of International Environmental Law, Oxford: Oxford University Press, 995-1009.

Litfin, K.T. 1999. "Environmental Remote Sensing, Global Governance, and the Territorial State." In: M. Hewson and T.J. Sinclair, eds., Approaches to Global Governance Theory. Albany, NY: State University of New York Press, 73-96.

Malaith, G.J. and S. Morris. 2002. "Repeated Games with Almost-Public Monitoring." Journal of Economic Theory 102(1): 189-228.

Mavroidis, P.C. 1992. "Surveillance Schemes: The GATT's New Trade Policy Review Mechanism." Michigan Journal of International Law 13: 374-414.

OECD. 2003. Peer Review: A Tool for Co-operation and Change. OECD Policy Brief. December.

Pagani, F. 2002. Peer Review: A Tool for Co-operation and Change -- An Analysis of an OECD Working Method. Report SG/LEG(2002)1. Paris: OECD.

Schafer, A. 2006. "A New Form of Governance? Comparing the Open Method of Co-ordination to Multilateral Surveillance by the IMF and the OECD." Journal European Public Policy13(1): 7088.

Schelling, Thomas C. 1956. "An Essay on Bargaining." American Economic Review 46(3): 281306.

United Nations. 1995. Berlin Mandate. Decision 1/CP.1, U.N. Framework Convention on Climate Change. Internet: http://unfccc.int/resource/docs/cop1/07a01.pdf.

UNEP. 2012. ODS Consumption in ODP Tons. Accessed March 1, 2012. Internet: http://ozone.unep.org/new site/en/Information/generate report.php?calculated field=ODS+C onsumption\&grouping option=Cntry\&incl baseline=1\&cntry=CN\&all anxgrp=on\&anxgrp=AI\&a nxgrp=All\&anxgrp=BI\&anxgrp=B II\&anxgrp=BIII\&anxgrp=CI\&anxgrp=CII\&anxgrp=CIII\&anxgrp=EI \&summary=0\&Yr1=1990\&Yr2=2011

UNFCCC. 2012. Greenhouse Gas Inventory Data - Detailed Data by Party. Accessed March 1, 2012. Internet: 
http://unfccc.int/di/DetailedByParty/Event.do;jsessionid=CD2F85D1574D60F06B8B092E620903 04.diprod01?event=go.

U.S. Energy Information Administration. 1997. Annual Energy Outlook 1997. Washington, DC: Department of Energy.

U.S. Energy Information Administration. 2012a. Annual Energy Outlook 2012. Washington, DC: Department of Energy.

U.S. Energy Information Administration. 2012b. International Energy Statistics. Accessed March 1, 2012. Internet: http://www.eia.gov/cfapps/ipdbproject/IEDIndex3.cfm.

Wara, Michael. 2007. "Is the Global Carbon Market Working?” Nature 445: 595-596.

Wettestad, Jorgen. 2007. "Monitoring and Verification." In: Bodansky, Daniel, Jutta Brunee, and Ellen Hey, eds. The Oxford Handbook of International Environmental Law, Oxford: Oxford University Press, 974-994.

World Resources Institute. 2012. Climate Analysis Indicators Tool. Accessed March 1, 2012. Internet: http://cait.wri.org. 
Tables and Figures 
Table 1. International Systems of Policy Surveillance

\begin{tabular}{|c|c|c|c|c|c|c|}
\hline Policy & Economic Policy & Economic Policy & Trade Policy & \begin{tabular}{|l|} 
Fossil Fuel \\
Subsidies \\
\end{tabular} & $\begin{array}{l}\text { Greenhouse Gas } \\
\text { Emissions }\end{array}$ & Climate Policy \\
\hline Institution & IMF & OECD & WTO & G-20 & UNFCCC & UNFCCC \\
\hline Review Mechanism & $\begin{array}{l}\text { Article IV } \\
\text { Consultation }\end{array}$ & $\begin{array}{l}\text { Economic and } \\
\text { Development } \\
\text { Review Committee }\end{array}$ & $\begin{array}{l}\text { Trade Review } \\
\text { Policy Board }\end{array}$ & $\begin{array}{l}\text { IEA, OECD, OPEC, } \\
\text { World Bank joint } \\
\text { report }\end{array}$ & $\begin{array}{l}\text { Subsidiary Body } \\
\text { for } \\
\text { Implementation }\end{array}$ & $\begin{array}{l}\text { Subsidiary Body } \\
\text { for } \\
\text { Implementation }\end{array}$ \\
\hline $\begin{array}{l}\text { Countries } \\
\text { Reviewed }\end{array}$ & All IMF members & All OECD members & All WTO members & All G-20 members & $\begin{array}{l}\text { Only [36] Annex } \\
\text { I countries }\end{array}$ & $\begin{array}{l}\text { Only [36] Annex } \\
\text { I countries }\end{array}$ \\
\hline Peer Review & Yes & Yes & Yes & Yes & No & No \\
\hline $\begin{array}{l}\text { Standards for } \\
\text { Reporting }\end{array}$ & Yes & & Yes & No & Yes & Yes \\
\hline $\begin{array}{l}\text { Technical } \\
\text { Assistance to Least } \\
\text { Developed } \\
\text { Countries }\end{array}$ & & $N / A$ & Yes & $N / A$ & $\mathrm{~N} / \mathrm{A}$ & $\mathrm{N} / \mathrm{A}$ \\
\hline Frequency & 1-2 years & 1-2 years & 2-6 years & Annual & Annual & $\sim 4$ years \\
\hline Country Visit & Yes & Yes & Typically & No & $\begin{array}{l}\text { Yes (every five } \\
\text { years) }\end{array}$ & No \\
\hline Published Review & Yes & Yes & Yes & Yes & {$[\mathrm{No}]$} & {$[\mathrm{No}]$} \\
\hline
\end{tabular}


Figure 1. Annex I Greenhouse Gas Emissions, 1997-2009

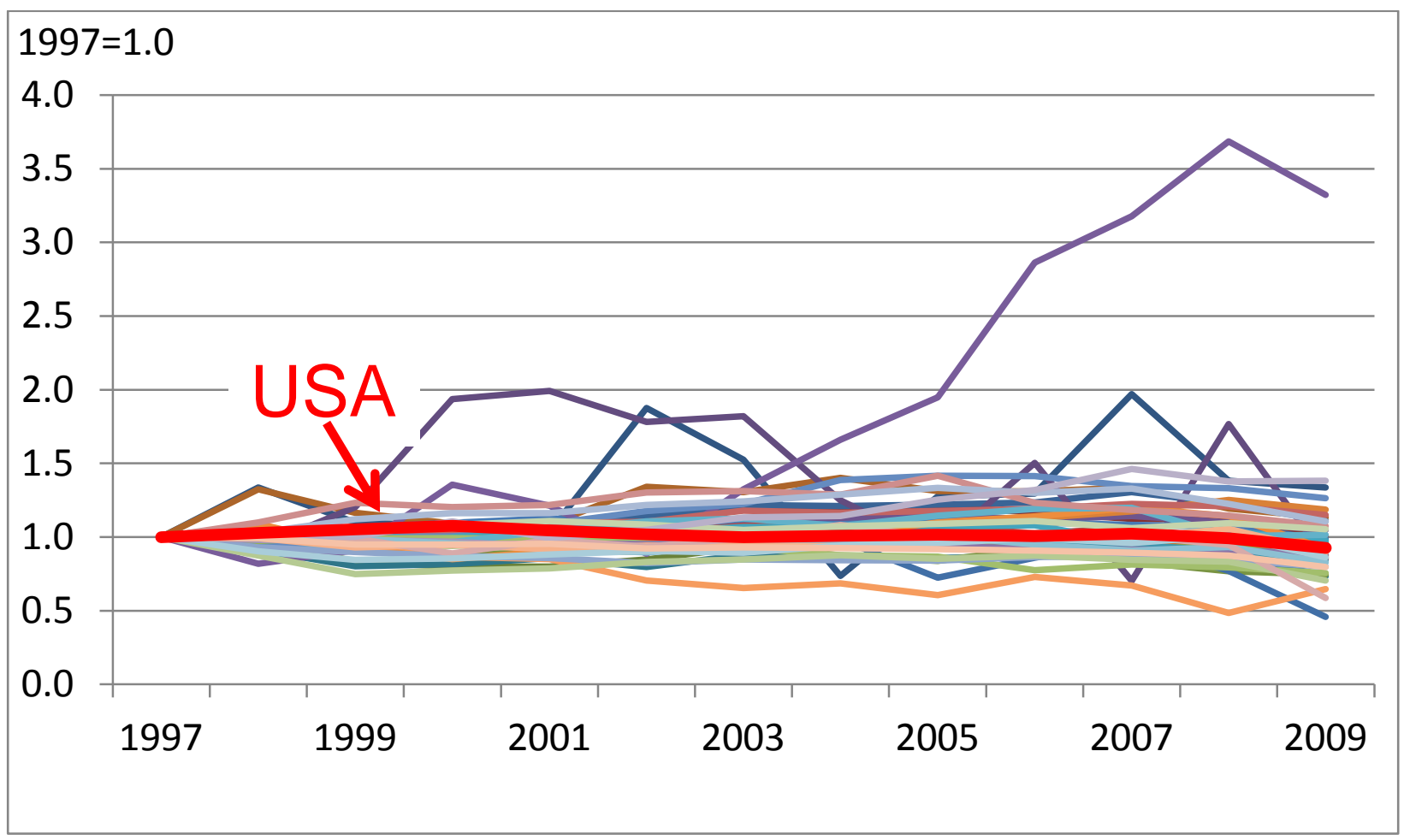

Source: UNFCCC 2012 
Figure 2. U.S. Carbon Dioxide Emissions, Actual 1990-2010 and Forecast 1997-2010

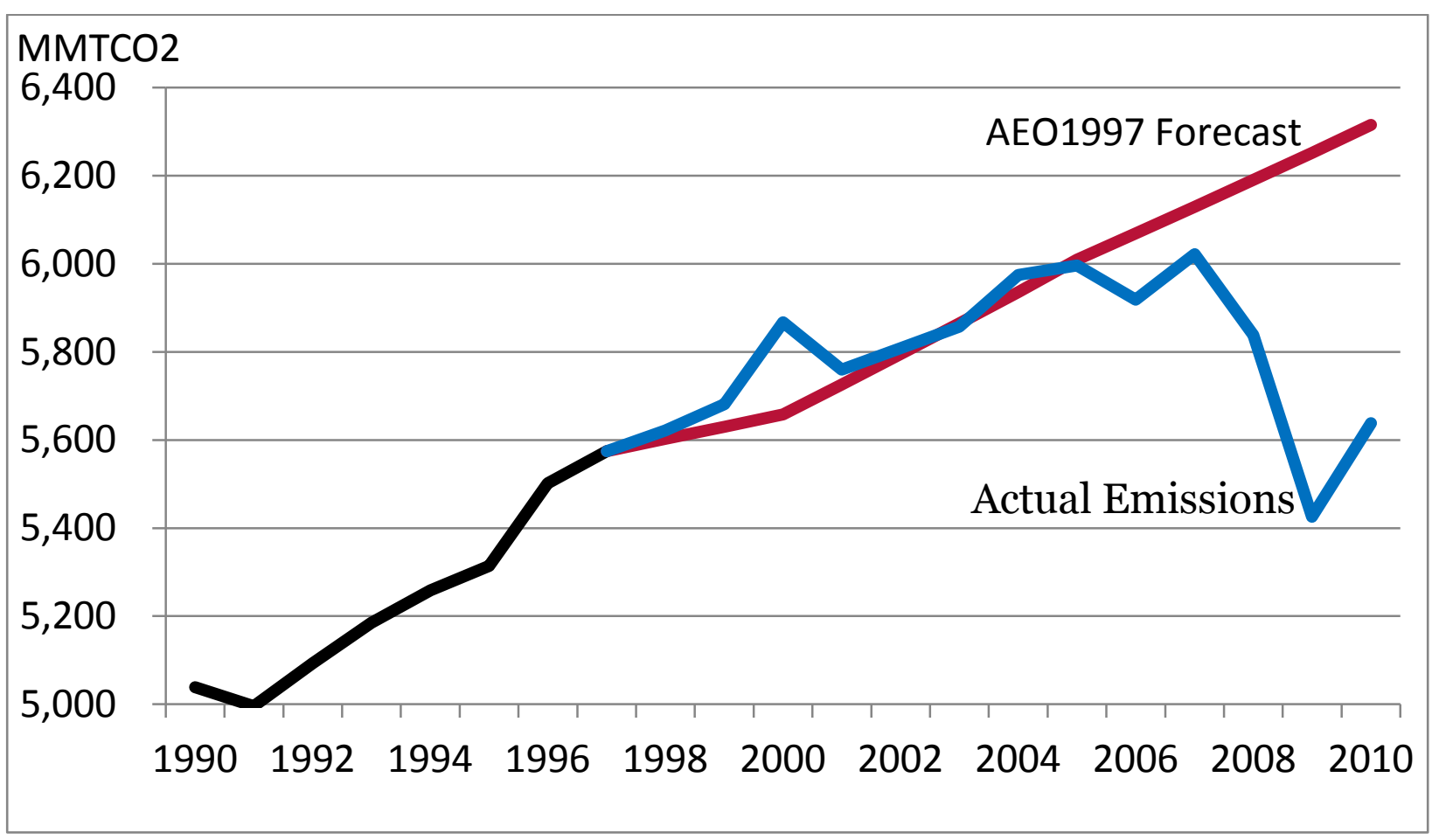

Source: U.S. EIA 1997, 2012. 